\title{
Influence of Colloidal Silver Nanoparticles on the Performance of Novel Flower-Like Titanium Dioxide Oxygen Sensor
}

\author{
Luis Castañeda* \\ Instituto de Física, Universidad Nacional Autónoma de Puebla, \\ Apartado Postal J-48, Puebla 72570, México
}

(Received May 4, 2008; accepted July 30, 2008)

Key words: thin films, vapor deposition, electrical properties

Titanium dioxide $\left(\mathrm{TiO}_{2}\right.$-anatase phase) thin films, consisting of agglomerated, flower-like nanoparticles, have been synthesized using an ultrasonic spray pyrolysis (USP) method in combination with titanium (IV) oxide acetylacetonate [TiO(acac) $\left.{ }_{2}\right]$ and methanol at $550^{\circ} \mathrm{C}$. These thin films were subsequently thermally treated in air at $950^{\circ} \mathrm{C}$ for $6 \mathrm{~h}$, and the flower-like particles were transformed into smooth surfaces mainly comprising the $\mathrm{TiO}_{2}$-rutile phase. In order to prepare oxygen sensors, $\mathrm{TiO}_{2}$ thin films were deposited on interdigitated gold electrodes in contact with alumina substrates. The silver colloidal solution was impregnated on the $\mathrm{TiO}_{2}$ thin film. Since the solvent in which the silver nanoparticles are suspended evaporates at $200^{\circ} \mathrm{C}$, the thin films were then annealed at this temperature in air for $1 \mathrm{~h}$. The effect of colloidal silver nanoparticles on the response of the thin-film $\mathrm{TiO}_{2}$ oxygen sensors was studied in a mixture with zero-grade air. The gas-sensing properties of $\mathrm{TiO}_{2}$ sensors in an atmosphere of $10^{4} \mathrm{ppm}$ oxygen were measured between 25 and $500^{\circ} \mathrm{C}$. The experimental results obtained with colloidal silver nanoparticles as surface additives show that the sensitivity reaches constant values for the $\mathrm{TiO}_{2}$-anatase and $\mathrm{TiO}_{2}$-rutile phases of 0.40 and 0.03 , respectively, at an $\mathrm{O}_{2}$ concentration of $100 \mathrm{ppm}$ in zero-grade air at $300^{\circ} \mathrm{C}$, which is as high as the values reported for oxygen sensors prepared by more expensive techniques.

\section{Introduction}

Interest has grown in reducing the quantities of air pollutant gases emitted during combustion processes. To reduce this environmental pollution and preserve the ecosystem, semiconductor gas sensors based on metal oxides that are of low cost and have high sensitivity to pollutant gases have been implemented. In particular, those made of semi-conducting metal oxides and titanium dioxide $\left[\mathrm{TiO}_{2}\right]$ have attracted

*Corresponding author: e-mail: luisca@sirio.ifuap.buap.mx 
the attention of many users and scientists interested in gas-sensing under a variety of conditions. The crystal structure of $\mathrm{TiO}_{2}$ has three forms: brookite and anatase (metastable phases), and rutile (a thermodynamically stable phase), although the most common are anatase and rutile. The differences in structure affect the catalytic or gas-sensing properties of titanium-based devices.

Oxygen molecules adsorbing or reacting on semiconducting metal oxide surfaces induce an observable change in surface resistivity. As a result, semiconducting metal oxide materials, such as $\mathrm{TiO}_{2}$, are often used as gas sensors by monitoring the changes in the surface electrical resistivity in the presence of oxygen molecules. The deposition of catalysts on semiconducting metal oxide surfaces was reported to improve the sensing performance in many studies..$^{(1,2)}$ Ideally, a gas sensor should be highly selective and sensitive to the target molecule, have a short response time, be very stable, and require low power to operate. ${ }^{(3,4)}$

In this work we explored the gas-sensing properties of the $\mathrm{TiO}_{2}$-anatase and $\mathrm{TiO}_{2}$ rutile phases. $\mathrm{TiO}_{2}$ thin films with well-characterized anatase and rutile structures were used in gas sensitivity measurements. At relatively high temperatures (between 425 and $475^{\circ} \mathrm{C}$ ) and without any additives, novel flower-like anatase and rutile thin films exhibited a very slow response to oxygen. Adding colloidal silver nanoparticles to anatase and rutile thin films makes them sensitive to oxygen and modifies their response speed and characteristics. The experiments reported in this paper have been carried out as a fundamental study on the physical properties of $\mathrm{TiO}_{2}$-based samples deposited by an inexpensive ultrasonic spray pyrolysis technique. ${ }^{(5,6)}$ The main purpose of the study was to explore their potential for development as oxygen sensor devices as a practical alternative to expensive solid-state electronic gas sensors.

\section{Experimental Details}

\subsection{Fabrication of novel flower-like titanium dioxide thin films}

Ultrasonic spray pyrolysis is a versatile technique able to produce nanoscale powders and thin films. By varying the concentration of the source solution and the atomization parameters, ${ }^{(5,6)}$ the particle size can be easily controlled in the nanoscale powders. $\mathrm{TiO}_{2}$ films were prepared using ultrasonic spray pyrolysis (Fig. 1). The deposition system includes a piezoelectric transducer operating at variable frequency, which was set to $1.2 \mathrm{MHz}$. The starting solution was prepared by dissolving titanium (IV) oxide acetylacetonate $\left[\mathrm{TiO}\left[\mathrm{CH}_{3} \mathrm{COH}=\mathrm{C}\left(\mathrm{O}^{-}\right) \mathrm{CH}_{3}\right]_{2}\right]$ (Aldrich) in pure methyl alcohol $\left[\mathrm{CH}_{3} \mathrm{OH}\right]$ (Baker) at $0.05 \mathrm{M}$ concentration. Alumina $\left[\mathrm{Al}_{2} \mathrm{O}_{3}\right]$ substrates (Coors Ceramics Company) (size $1.25 \mathrm{~cm} \times 1.25 \mathrm{~cm}$ ) were used to grow the thin-film oxygen-sensing devices and to electrically characterize them at temperatures between 25 and $500^{\circ} \mathrm{C}$. All substrates were ultrasonically cleaned with trichloroethylene $\left[\mathrm{ClCH}=\mathrm{CCl}_{2}\right](\mathrm{Baker})$, acetone $\left[\mathrm{CH}_{3} \mathrm{COCH}_{3}\right]$ (Baker), and methyl alcohol $\left[\mathrm{CH}_{3} \mathrm{OH}\right]$ (Baker), and dried under a nitrogen $\left[\mathrm{N}_{2}\right]$ (Praxair) flow. The substrate temperature during the spray deposition was set to $550^{\circ} \mathrm{C}$ within an accuracy of $\pm 1^{\circ} \mathrm{C}$, and filtered air was used as a carrier and director gas at flow rates of 3.5 and $0.5 \mathrm{~L} \mathrm{~min}^{-1}$, respectively, within an accuracy of \pm $0.5 \mathrm{~L} \mathrm{~min}^{-1}$. The deposition time was set to $7.5 \mathrm{~min}$ within an accuracy of $\pm 0.1 \mathrm{~min}$. 


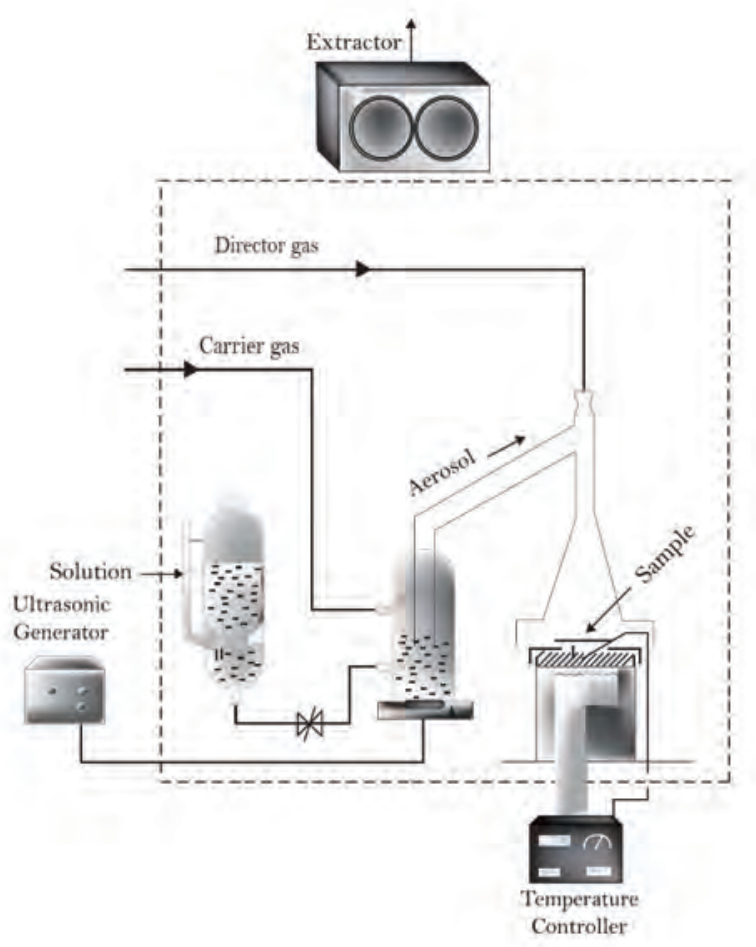

Fig. 1. Schematic diagram of the ultrasonic spray pyrolysis (USP) system used to deposit novel flower-like $\mathrm{TiO}_{2}$-anatase phase thin films.

Subsequently, in order to promote structural changes from the anatase to the rutile phase in the nanostructures and crystallization of the rutile phase, the samples were annealed at $950^{\circ} \mathrm{C}$ in air for $6 \mathrm{~h}$.

\subsection{Morphological characterization of $\mathrm{TiO}_{2}$ thin solid films}

The morphology of the films was studied by scanning electron microscopy (SEM) in an LV JEOL 5600 electron microscope. Before observations were made, the samples were coated with a very thin metallic deposit in order to improve the resolution of the micrographs, which in turn were directly recorded by a PC system connected to the microscope. The physical characterization of $\mathrm{TiO}_{2}$ thin solid films was reported in a previous article. ${ }^{(6)}$

\subsection{Scanning electron microscopy results}

Figure 2(a) shows an SEM image of the $\mathrm{TiO}_{2}$ sample deposited at $T_{\mathrm{s}}=550^{\circ} \mathrm{C}$, which corresponds to the anatase crystalline structure. From this micrograph, it is 

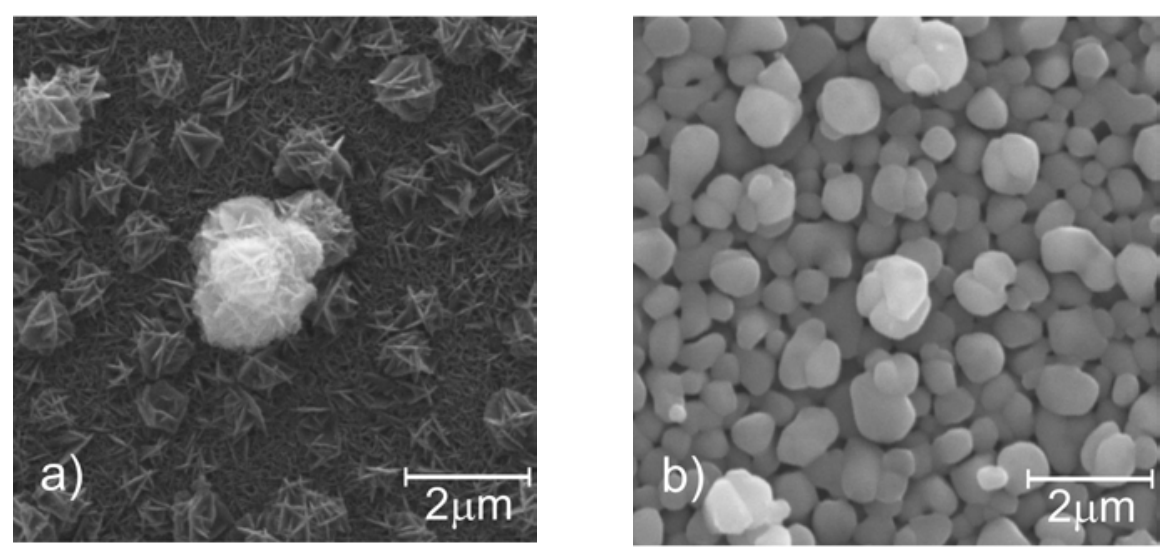

Fig. 2. (a) $\mathrm{SEM}$ micrograph of as-deposited $\mathrm{TiO}_{2}$ thin film at $T_{\mathrm{s}}=550^{\circ} \mathrm{C}$ showing flower-like radial nanoarrays of $\mathrm{TiO}_{2}$ platelets. (b) $\mathrm{SEM}$ micrograph of annealed $\mathrm{TiO}_{2}$ thin film at $950^{\circ} \mathrm{C}$ for $6 \mathrm{~h}$ in air. Here the flower-like structures are transformed into large particles exhibiting a smooth surface structure (rutile phase).

possible to observe that the as-deposited material consists of flower-like structures of agglomerated platelets of $\mathrm{TiO}_{2}$ arranged radially.(6) An SEM image of a typical annealed sample is displayed in Fig. 2(b). Here it is clear that the annealing process resulted in two structural alterations: i) the disappearance of the flower-like structure within the nanostructures and ii) changes in the morphology and size of the particles, which resulted in the formation of smooth rutile particles. In addition, some of these particles were sintered and formed larger particles of rutile.

\subsection{Fabrication of oxygen sensors}

As a first step, interdigitated electrodes were deposited on $\mathrm{Al}_{2} \mathrm{O}_{3}$ substrates by the vacuum thermal evaporation of gold [Au] wire $(0.5 \mathrm{~mm}$ diam., $99.999 \%$ (Aldrich)) through a metal mask. The spacing between the electrode fingers was set to approximately $1.1 \mathrm{~mm}$ with a thickness of $1.5 \mu \mathrm{m}$ (Fig. 3). Afterwards, oxygen sensors were produced using the experimental conditions mentioned in the previous section for $\mathrm{TiO}_{2}$-anatase and $\mathrm{TiO}_{2}$-rutile phase thin films.

\subsection{Incorporation of colloidal silver nanoparticles on novel flower-like} titanium dioxide thin films

The purpose of incorporating colloidal silver nanoparticles in the metal oxide semiconductor is to increase the speed of the chemical reaction during gas detection. This is reflected in the electrical properties by increasing the sensitivity to oxygen. Colloidal silver nanoparticles were incorporated on the surfaces of the $\mathrm{TiO}_{2}$-anatase and $\mathrm{TiO}_{2}$-rutile phase thin films by the following procedure.

First, of all colloidal silver nanoparticles were synthesized as follows: i) $0.1 \mathrm{~g}$ 


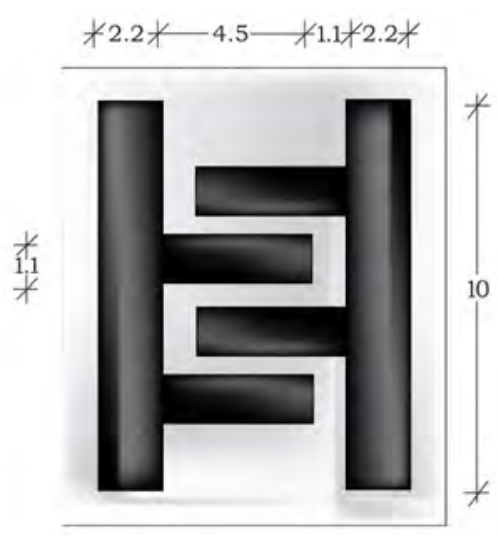

Fig. 3. Top view of a sensor with an interdigitated electrode structure to measure the electrical resistance of oxygen-sensitive material (dimensions in $\mathrm{mm}$ ).

of a $99.99 \%$ pure sample of silver nitrate $\left[\mathrm{AgNO}_{3}\right]$ (Aldrich) was placed in a $10 \mathrm{ml}$ beaker. Using a Pasteur pipette, two drops of concentrated nitric acid $\left[\mathrm{HNO}_{3}\right]$ (Baker) were added along with $5 \mathrm{ml}$ of ethyl alcohol $\left[\mathrm{C}_{2} \mathrm{H}_{5} \mathrm{OH}\right]$ (Baker). ii) Afterwards, $0.5 \mathrm{~g}$ of hexadecanol $\left[\mathrm{C}_{16} \mathrm{H}_{34} \mathrm{O}\right]$ (Aldrich) was dissolved in $5 \mathrm{~mL}$ of $\mathrm{C}_{2} \mathrm{H}_{5} \mathrm{OH}$. The $\mathrm{AgNO}_{3}$ solution, and $\mathrm{C}_{16} \mathrm{H}_{34} \mathrm{O}$ were placed in a $250 \mathrm{ml}$ flask, and $90 \mathrm{ml}$ of $\mathrm{C}_{2} \mathrm{H}_{5} \mathrm{OH}, 0.4 \mathrm{ml}$ of glycerol $\left[\mathrm{CH}_{2} \mathrm{OH}-\mathrm{CHOH}-\mathrm{CH}_{2} \mathrm{OH}\right]$ (Baker), and $57 \mu$ of hydrazine $\left[\mathrm{N}_{2} \mathrm{H}_{4}\right]$ (Baker) were added. iii) The flask was then agitated at a constant rate while maintained at $60^{\circ} \mathrm{C}$ for 12 h. It was then allowed to cool to room temperature and kept undisturbed for five days. After this period, the optical transmittance spectrum was obtained in the UV-Vis range. A band was observed at $460 \mathrm{~nm}$, indicating the formation of $120 \mathrm{~nm}$ nanoparticles. ${ }^{(7)}$ Optical transmittance spectra of the Ag nanoparticles in the range from 200 to 1000 $\mathrm{nm}$ were obtained using a double-beam spectrophotometer (Shimadzu UV-Vis model 260), with air as the reference. iv) The previously mentioned colloidal solution was impregnated on the $\mathrm{TiO}_{2}$ films by applying 100 brushstrokes by the "paint on" method, using a brush. v). Since the solvent in which the silver nanoparticles were suspended evaporates at $200^{\circ} \mathrm{C}$, the film was then annealed at this temperature in air for $1 \mathrm{~h}$.

Rutherford backscattering spectrometry (RBS) analysis was used to study the elemental composition of the film. RBS is a very sensitive, accurate, and nondestructive nuclear technique that allows the identification of the atomic masses and determination of the distribution of the elements present in the sample as a function of depth below the surface. RBS analysis was performed in the 3MV tandem accelerator (NEC 9SDH-2 Pelletron) facility at the Instituto de Física of the Universidad Nacional Autónoma de México (UNAM). A collimated $3 \mathrm{MeV} \alpha$-particle beam of $1.5 \mathrm{~mm}$ diameter was used as the projectile. After the collision, the scattered $\alpha$-particles were detected using a surface barrier detector placed at $168^{\circ}$ to the beam. The simulation and analysis of the RBS spectrum were performed using the SIMNRA code. 


\subsection{Characterization of oxygen sensors}

Oxygen sensor characterization was carried out by placing the sensors in a sample holder in a measurement chamber with a vacuum capacity of $10^{-6}$ Torr. The measurement chamber allowed the controlled and simultaneous introduction of different gases. The electrical conductivity response was measured by monitoring the DC current under a constant bias voltage of $5 \mathrm{~V}$ from a DC power supply (Keithley model 230) and an electrometer (Keithley model 619). At this bias voltage, the current-voltage behavior was ohmic. A schematic of the characterization system is shown in Fig. 4. The ambient gas under consideration was zero-grade air [composition: $\mathrm{O}_{2} 19.5-23.5 \%, \mathrm{H}_{2} \mathrm{O}<3 \mathrm{ppm}$, $\mathrm{CO}_{2}<3 \mathrm{ppm}$, (total hydrocarbon content) $\mathrm{THC}<1 \mathrm{ppm}$ ] (Praxiar), and the gas detected was oxygen $\left[\mathrm{O}_{2}\right]$ (Praxiar) added in excess to the reference zero-grade air. The gas concentration in the ambient gas atmosphere was controlled using a Lenox Laser flux control system.

Sensor characterization was performed by measuring the change in the electrical resistance $(\Delta R)$ of the active film as a result of its interaction with the $\mathrm{O}_{2}$. This change in the electrical resistance was measured as a function of two main parameters: i) temperature during measurements under a given ambient gas concentration, which allowed the determination of the optimal operating temperature of the sensor, and

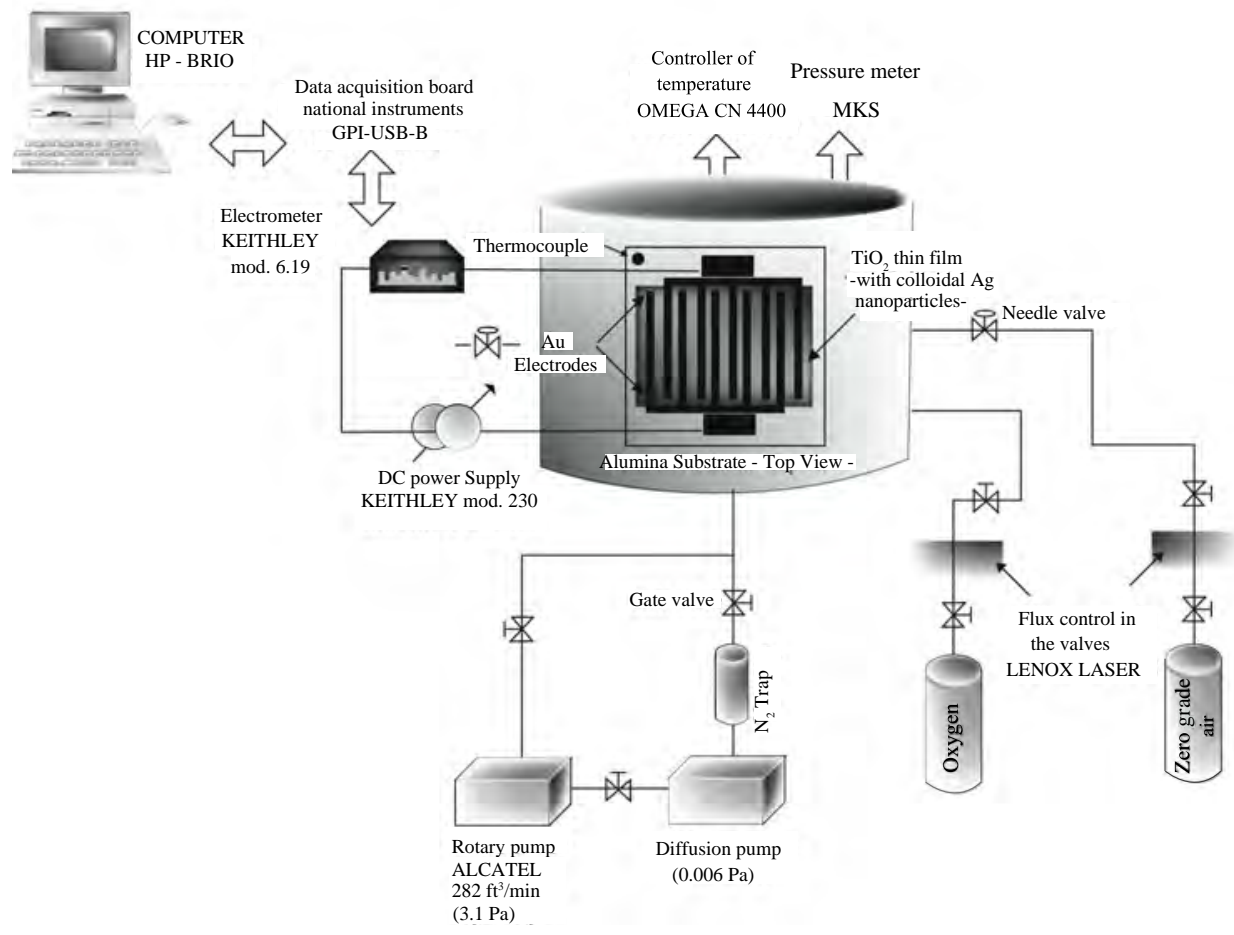

Fig. 4. Schematic diagram of the system used to measure electrical properties under controlled atmospheres and temperatures. 
ii) $\mathrm{O}_{2}$ concentration at constant temperature during measurement, which allowed the determination of the sensor sensitivity $(S)$. This latter parameter was defined as a function of the relative difference in resistances with respect to $\mathrm{O}_{2}$ concentration as follows: ${ }^{(8,9)}$

$$
S=\frac{R_{\text {gas }}-R_{0}}{R_{0}}
$$

where $R_{\text {gas }}$ and $R_{0}$ are the thin-film resistances measured in oxygen and zero-grade air, respectively, i.e., the minimum concentration of $\mathrm{O}_{2}$ at which the sensor exhibits an appreciable response. In both cases, changes in the electrical resistance of the active film as a function of the exposure time to the gas mixture were measured after stabilization at a constant value or a saturation value was reached. Note that the response time of a sensor is defined as the time required to reach $90 \%$ of its saturation value (in this case, the $\Delta R$ parameter). Once this level was achieved, the detected gas was quickly removed from the ambient atmosphere (in other words, the oxygen valve was closed in approximately $1 \mathrm{~s}$ ) to determine the reversibility of the detection process. If the detection process is reversible, then the electrical resistance of the active layer will exhibit the same value as it had before exposure to oxygen.

\section{Results and Discussion}

The RBS analysis performed on one of the samples impregnated with colloidal silver nanoparticles showed the presence of silver from the surface to $670 \pm 47 \mathrm{~nm}$ inside the film. The analysis also showed that silver was not homogeneously deposited or that it diffused inside the film during the annealing process, as can be observed in the RBS spectrum depicted in Fig. 5, where the presence of three zones with different silver concentrations are observed. The first zone can be seen as a small peak in the right side of the spectrum in Fig. 5 that corresponds to a layer containing 7\% Ag and 93\% $\mathrm{O}$ from the surface to $250 \pm 18 \mathrm{~nm}$ inside the film. The high concentration of oxygen in the whole sample corresponds to an oxidation process that took place in the film during the heating and/or annealing processes, as well as to the large amount of oxygen atoms present in the starting solution $\left(\mathrm{TiO}\left[\mathrm{CH}_{3} \mathrm{COH}=\mathrm{C}\left(\mathrm{O}^{-}\right) \mathrm{CH}_{3}\right]_{2}, \mathrm{CH}_{3} \mathrm{OH}\right.$ and $\left.\mathrm{Al}_{2} \mathrm{O}_{3}\right)$ and in the $\mathrm{AgNO}_{3}$. The second layer corresponds to an intermediate layer where silver, oxygen, and titanium coexist, showing an elemental composition of $45 \% \mathrm{Ag}, 10 \% \mathrm{O}$, and $45 \%$ Ti. The thickness of the second layer is $250 \pm 18 \mathrm{~nm}$, and from the elemental composition results of layers one and two, it can be seen that silver migrated from surface to this second layer, reaching a maximum concentration at $370 \pm 26 \mathrm{~nm}$ inside the sample. The third layer had a thickness of $170 \pm 12 \mathrm{~nm}$ and a composition of $10 \% \mathrm{Ag}, 78 \% \mathrm{O}$, and $12 \%$ Ti. The remainder of the film did not contain any silver, but only oxygen, titanium, and aluminum.

Oxygen-gas-sensing devices based on titanium dioxide thin films without catalysts deposited at a substrate temperature of $550^{\circ} \mathrm{C}$ (deposition conditions identical to those mentioned in $\S 2$ and annealed at $950^{\circ} \mathrm{C}$ for $6 \mathrm{~h}$ in air were analyzed by considering 


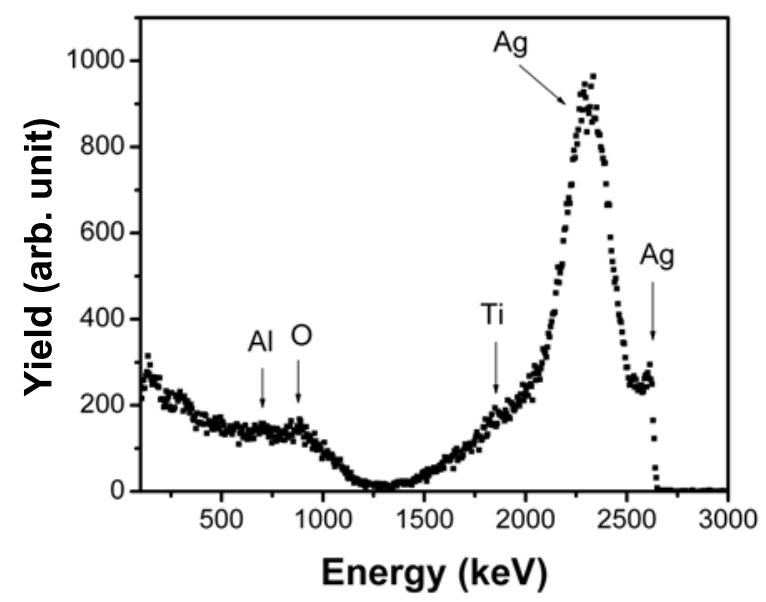

Fig. 5. RBS spectrum of a $\mathrm{TiO}_{2}$-anatase phase film containing colloidal silver nanoparticles.

the electrical resistance as a function of the oxygen concentration $(10,000 \mathrm{ppm})$ for the temperature range from 25 to $500^{\circ} \mathrm{C}$. The main goal of annealing our samples, other than to allow the sintering of the powders, was to induce a phase change from anatase to rutile. In both cases, extremely small variations in electrical resistance were detected, with signal levels being similar to instrumental noise. Thus, due to this noisy behavior it was not possible to calculate sensitivity. Note that no resistance measurements were made at higher operating temperatures due to the limitations of the heating system used to warm the devices.

A possible explanation for the behavior of the electrical resistance is as follows: after annealing, near-stoichiometric titanium dioxide may be produced. Considering the width of the prohibited band in the rutile phase $(3.4 \mathrm{eV})$ and the possible widening effect of this band due to the material's porosity, an excellent insulating material is obtained in terms of electrical characteristics. This effect is most clearly observed when electrical resistance is measured along the film plane with an electrode separation on the order of $1 \mathrm{~mm}$, resulting in an oxide with an electrical resistance of about $1 \times 10^{13} \Omega$.

Samples impregnated with colloidal silver nanoparticles exhibit a variation in sensitivity as a function of measurement temperature for a constant oxygen concentration. Figure 6 displays this sensitivity for measurement temperatures ranging from 25 to 500 ${ }^{\circ} \mathrm{C}$ for a $1,000 \mathrm{ppm}$ oxygen concentration for $\mathrm{TiO}_{2}$-anatase phase thin films. Comparing this with the curve obtained for devices with $\mathrm{TiO}_{2}$-rutile phase thin films having colloidal silver nanoparticles (Fig. 7), the maximum magnitude of sensitivity observed with $\mathrm{TiO}_{2}-$ rutile phase thin films is half of that obtained with $\mathrm{TiO}_{2}$-anatase phase thin films. This effect may again be explained by considering the low reactivity of the titanium dioxide rutile phase. This result may be associated with the porous microstructure of the active film. Since the mechanism of gas detection is fundamentally a surface phenomenon, the 


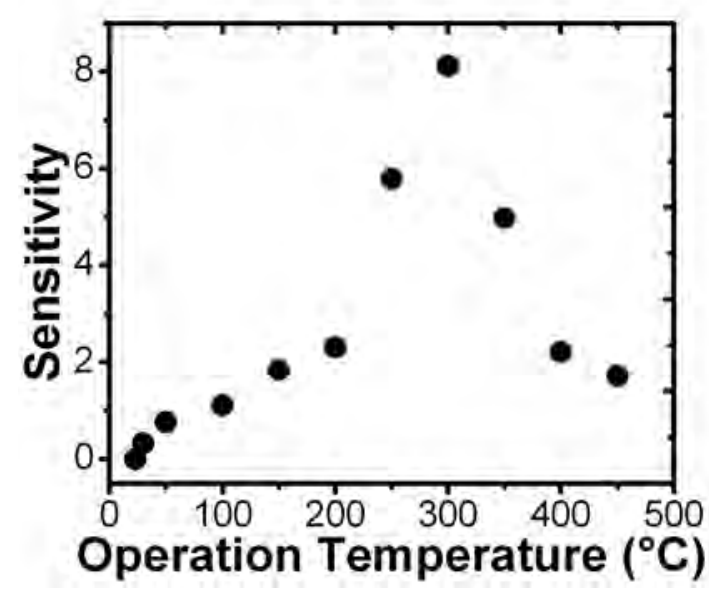

Fig. 6. Sensitivity variation of the novel flower-like $\mathrm{TiO}_{2}$-anatase phase oxygen sensor based on the incorporation of colloidal silver nanoparticles as a catalyst as a function of temperature with $\mathrm{O}_{2}$ concentration of $1,000 \mathrm{ppm}$ diluted by zero-grade air.

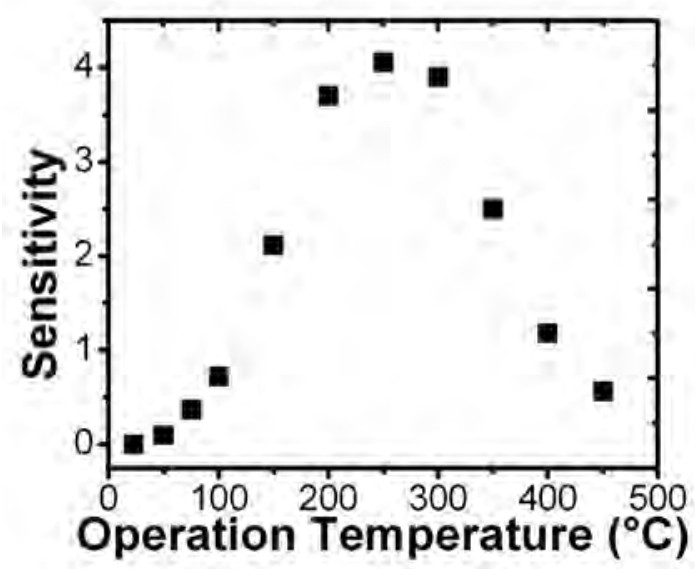

Fig. 7. Sensitivity variation of a $\mathrm{TiO}_{2}$-rutile phase oxygen sensor based on the incorporation of colloidal silver nanoparticles as a catalyst as a function of temperature for a 1,000 ppm concentration of $\mathrm{O}_{2}$ diluted by zero-grade air.

use of porous films in which the surface/volume coefficient is as large as possible must in principle increase the magnitude of the sensitivity. On the other hand, depending on the dimensions of the pores, they may also have some effect on the structure of the electronic energy states and thus on the surface conditions of the material, which may in turn explain the difference observed in the optimal operating temperatures. 
Figure 8 displays the sensitivity of the $\mathrm{TiO}_{2}$-anatase phase oxygen-sensing device incorporating colloidal silver nanoparticles as a catalyst as a function of oxygen concentration for a constant temperature of $300^{\circ} \mathrm{C}$. An increase in the sensitivity is observed as oxygen concentration increases.

The response time for the gas sensor was on average on the order of $60 \mathrm{~s}$ at a temperature of $300^{\circ} \mathrm{C}$ with excess oxygen concentrations in the 100 to $1,000 \mathrm{ppm}$ range. Correspondingly, the average recuperation time of the oxygen sensor for the same excess oxygen concentrations and temperature was on the order of $1700 \mathrm{~s}$.

Generally, oxygen sensors based on the incorporation of colloidal silver nanoparticles on the surface of $\mathrm{TiO}_{2}$ films may be examined in accordance with Fig. 9 by considering that the reaction with molecular oxygen that occurs with the intervention of the catalyst is the following:

$$
2 M(s) \cdot+\mathrm{O}_{2} \rightarrow 2 M(s)+2 \mathrm{O}^{-},
$$

where $M(s)$ is the transition-metal catalyst. Molecular oxygen at the catalyst is dissociated and, as a result, ionic bonds are formed between the catalyst and the oxygen. Atomic oxygen produced in this way migrates on the surface of the material, as was observed in the RBS results, where the following reaction takes place:

$$
\mathrm{O}+e^{-} \rightarrow \mathrm{O}^{-}
$$

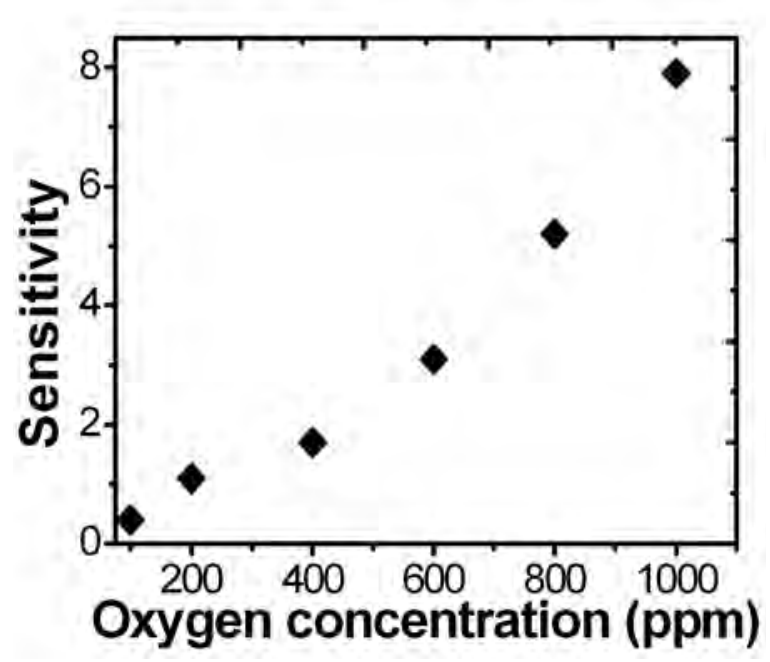

Fig. 8. Sensitivity dependence of the novel flower-like $\mathrm{TiO}_{2}$-anatase phase oxygen sensor based on the incorporation of colloidal silver nanoparticles as a catalyst as a function of the oxygen concentration diluted by zero-grade air at a temperature of $300^{\circ} \mathrm{C}$. 


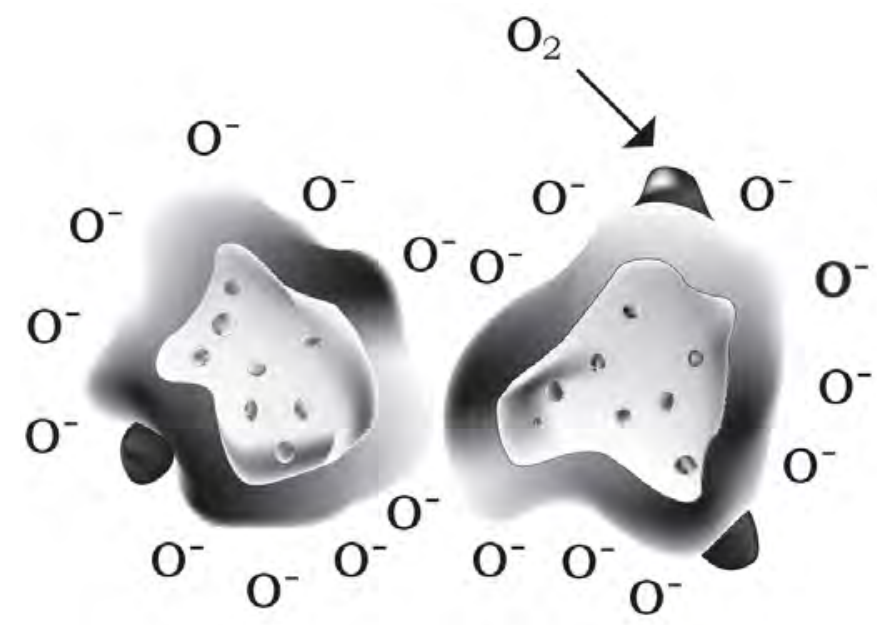

Fig. 9. Outline of the molecular oxygen reaction occurring with the intervention of a catalyst.

In the chemical reaction described by eq. (3), the atomic oxygen, generated through the action of the catalyst on the molecular oxygen, removes an electron from the active $\mathrm{TiO}_{2}$ film and becomes negatively ionized. This removal of electrons from the surface of the active film creates a surface layer with a conducting electron concentration smaller than that in the volume, thereby producing an increase in the active layer's electrical resistance.

The action of a catalyst incorporated on the surface of the active layer formed by a polycrystalline material is, in general, considered to take place in the following way. i) The catalyst increases the response speed as well as the sensitivity of the gas sensor, ii) the sensor operation temperature is likewise reduced, and iii) this result is linked to the fact that the molecular oxygen dissociation requires less energy to occur due to the catalyst's action.

\section{Conclusions}

Oxygen sensors based on novel flower-like titanium dioxide with colloidal silver nanoparticles have been designed for oxygen detection at high temperatures from 25 to $500^{\circ} \mathrm{C}$. From the point of view of the gas-sensing mechanism, these devices should be considered as sensors in which the diffusion of point defects plays the most important role in gas-solid interactions. In summary, novel flower-like titanium dioxide $\left(\mathrm{TiO}_{2}\right.$ anatase and $\mathrm{TiO}_{2}$-rutile phases) thin films with microstructural characteristics suitable for application to the manufacture of oxygen sensors have been prepared by ultrasonic spray pyrolysis. 


\section{Acknowledgments}

We are grateful to Instituto de Física, Universidad Autónoma de Puebla for the financial support. We also thank Armando Ortiz Rebollo for useful discussions.

\section{References}

1 P. K. Dutta, A. Ginwalla, B. Hogg, B. R. Patton, B. Chwieroth, Z. Liang, P. Gouma, M. Mills and S. Akbar: J. Phys. Chem., B 103 (1999) 4412.

2 Y. Shimizu, N. Kuwano, T. Hyodo and M. Egashira: Sens. Actuators, B 83 (2002) 195.

3 S. Semancik and R. Cavicchi: Acc. Chem. Res. 31 (1998) 279.

4 W. Göpel: Sens. Actuators 16 (1989) 167.

5 L. Castañeda, J. C. Alonso, A. Ortiz, E. Andrade, J. M. Saniger and J. G. Bañuelos: Mater. Chem. Phys. 77 (2002) 938.

6 L. Castañeda and M. Terrones: Physica, B 390 (2007) 143.

7 M. H. Ullah, K. Il and C-S. Ha: Mater. Lett. 60 (2006) 1496.

8 L. Castañeda: Mater. Sci. Eng., B 139 (2007) 149.

9 L. Castañeda, A. Maldonado and M. de la L. Olvera: Sens. Actuators, B 133 (2008) 687. 